Microbes and Health

ISSN: 2226-0153 (Print) 2305-3542 (Online)

http://journal.bsvmph.org/

Microbes and Health, June 2013, 2(1): 12-14

DOI: $10.3329 / \mathrm{mh} . \mathrm{v} 2 \mathrm{i} 1.17256$

\title{
Seroprevalence of Brucellosis and Its Associated Risk Factors in Bovine at Greater Mymensingh District of Bangladesh
}

\author{
Md. Ariful Islam, Laboni Akter, Mst. Minara Khatun and Md. Ariful Islam* \\ Department of Microbiology and Hygiene, Faculty of Veterinary Science, Bangladesh Agricultural University, Mymensingh-2202, \\ Bangladesh \\ *Corresponding author's e-mail: arifmicro2003@yahoo.com
}

[Received: 04 April 2013, Revised: 22 May 2013, Accepted: 30 May 2013]

A B S T R A C T

Brucellosis is a zoonotic bacterial disease of humans and animals caused by Gram negative bacteria of the genus Brucella. The study was conducted to determine the sero-prevalence of brucellosis and its associated risk factors in cattle and buffalo in greater Mymensingh district, Bangladesh. Blood samples were collected from cattle $(n=150)$ and buffalo $(n=60)$. Sera were tested for Brucella specific antibody by the rose Bengal plate test (RBPT). Overall prevalence of brucellosis was $15.33 \%$ in cattle and $13.33 \%$ in buffalo. Higher prevalence was recorded in cattle and buffalo of over 4 years age (18\% and $15.68 \%$, respectively). Female animals showed higher brucellosis prevalence (cattle 19.54\%, buffalo 13.46\%) than male ( cattle 8.21\%, buffalo 12.5\%). Pregnant cows showed higher prevalence of brucellosis (13.33\%) as compare to non pregnant cows $(10 \%)$. The prevalence of brucellosis was $10 \%$ in aborted cows, $4 \%$ in the case of retained placenta and $2.85 \%$ in repeat breeder cows. The study suggests that brucellosis is prevalent in the cattle and buffalo and its prevalence is affected by the animal's age, sex, pregnancy status and reproductive disorders.

Keywords: Seroprevalence, Brucellosis, Brucella, Cattle, Buffalo, Risk factor

(C) 2013 Microbes and Health. All rights reserved

\section{Introduction}

Brucellosis is a zoonotic disease caused by non-motile, coccobacilli, Gram-negative bacteria of the genus Brucella which show strong host preference. The species of Brucella which infect livestock and their primary hosts are: B. abortus (cattle), B. melitensis (goat), B ovis (sheep), B. suis (pig) (Islam et al., 2013). Brucellosis in domestic water buffalo (Bubalus bubalis) is mainly caused by B. abortus (Brahmabhatt et al., 2009).

Brucellosis is essentially a disease of sexually mature animals (Radostits et al., 2007). In male animals it causes infertility (Boschiroli et al., 2001; Gwida et al., 2010). In female animals, the most prominent clinical sign of brucellosis is abortion. Brucella localize in the -udder of the infected cattle and excrets via milk (England et al., 2004). Brucellosis is transmitted by direct or indirect contact with infected animals "often via ingestion and also via venereal routes" (Quinn et al., 1994). Other clinical signs of brucellosis in animals are repeat breeding, retained placenta and metritis (Shareef, 2006).

The epidemiology of brucellosis is complex and it is influenced by several factors (Nicoletti, 1980). Brucellosis is an occupational zoonosis that mainly infect livestock farmers and their families, abattoir workers, farm labors, slaughter-house workers, butchers and veterinarians (Yagupsky and Baron, 2005; Tabak et al., 2008; Behzadi and Mogheiseh, 2011).

The human brucellosis which is also called undulant or Malta fever, is a serious public health problem and has been reported in

To cite this article: Islam MA, L Akter, MM Khatun and MA Islam, 2013. Seroprevalence of brucellosis and its associated risk factors in bovine at greater Mymensingh district of Bangladesh. Microbes Health, 2(1): 12-14. many parts of the world such as; Asia, India, Middle Eastern, Southern European, and Latin American countries (Montanaro et al., 1992; Collier et al., 1998).

Bovine brucellosis has emerged as a serious animal and public health issue in many parts of the world (Corbel, 1997). It causes economic losses due to abortion or stillbirth, irregular breeding and loss of milk production especially in countries where rural income relies largely on livestock breeding and dairy products (Maadi et al., 2011). It is one of the most devastating transboundary animal diseases and also a major barrier for trade (Gul and Khan, 2007).

Brucellosis is endemic in Bangladesh (Amin et al., 2005; Das et al., 2008) where approximately $80 \%$ people live in villages, and the rural income is largely dependent on livestock. Peoples remain in close contact with domestic animal population owing to their occupation and face a constant risk of acquiring brucellosis.

The present study was undertaken to determine the seroprevalence of brucellosis in cattle and buffalo in Mymensingh, Tangail and Sherpur districts and its associated risk factors. Isolation of the Brucella spp. from the seropositive and aborted animals was also attempted.

\section{Materials and Methods}

The study was conducted for a period of 10 months (July 2011 to May 2012) at the Department of Microbiology and Hygiene, Bangladesh Agricultural University (BAU), Mymensingh.

\section{Sample collection}

Venous blood samples were aseptically collected from cattle $(\mathrm{n}=150)$ and buffalo $(\mathrm{n}=60)$ at breeding farm, Tangail, BAU dairy farm, Char Nillukia, Mymensingh sadar and Char Basur Algi, 
Nokla, Sherpur. Fetal stomach contents, fetal spleens, lymph nodes and lungs were aseptically collected from three aborted cows.

\section{Serological test}

Rose Bengal plate test (RBPT) was used to to detect $B$. abortus specific antibody in the serum samples. The antigen (B. abortus strain 119-3) was obtained from the laboratory of Veterinary Public Health, College of Veterinary Medicine, Chonbuk National University, Republic of Korea. The test was performed according to the standard procedures of OIE (2008). The test and control sera were homogenized using a vortex and $10 \mu \mathrm{l}$ of each serum was placed on a glass plate marked with circles of approximately $2 \mathrm{~cm}$ in diameter. After gently shaking the antigen vial $10 \mu \mathrm{l}$ of antigen was placed beside the serum drop. The antigen and serum were mixed on the plate for exactly $4 \mathrm{~min}$. Definite clumping/ agglutination was considered as a positive reaction, while no clumping/agglutination was the indication of negative reaction.

\section{Bacteriological study}

Blood samples of seropositive cattle $(n=23)$ and buffalo $(n=8)$ and specimens of fetal stomach contents, spleens, lymph nodes and lungs collected from three aborted animals were cultured on blood agar and brucella agar media for isolation of Brucella spp.

The tissue samples were processed according to the procedures described by Alton et al. (1975). Blood samples were processed by the lysis concentration method (Kolman et al., 1991) with some modifications. Briefly, $100 \mu \mathrm{l}$ blood sample was mixed with $900 \mu \mathrm{l}$ distilled water in an Eppondorf tube. Hemolysed blood samples were centrifuged at $1500 \mathrm{rpm}$ for 30 minutes at $4^{\circ} \mathrm{C}$ temperature. Supernatant was inoculated duplicate in blood agar and brucella agar media plates and incubated at $37^{\circ} \mathrm{C}$ for 5 days under $5 \% \mathrm{CO}_{2}$ atmosphere.

Fetal lymph nodes, lungs, spleens were also processed similarly after grinding in a morter with pestle.

\section{Statistical analysis}

Data were analyzed for statistical significance by Chi-square test (SPSS 11.5, UK). A $p$ value of $\leq 0.05$ was considered as statistically significant.

\section{Results}

The overall prevalence of brucellosis was $15.33 \%$ in cattle and $13.33 \%$ in buffalo. The highest prevalence was recorded in the cattle breeding farm, Tangail (22\%) followed by Char Basur Algi, Nokla, Sherpur (16.66), BAU dairy farm (5\%) and Char Nillukia (5\%) (Table 1).

Prevalence of brucellosis was found to increase with the increase of animal's age (Table 2). The highest prevalence was recorded in cattle and buffalo over 4 years of age $(18 \%$ and $15.68 \%$, respectively).

A higher prevalence of brucellosis was recorded in female as compared to male. In female cattle, the prevalence of brucellosis was $19.54 \%$ against $8.21 \%$ in male $(p<0.213)$. Similarly in female buffalo the prevalence was $13.46 \%$ while in males it was $12.5 \%(p<0.314)$.

Out of 150 cattle, 60 were pregnant and 90 were non-pregnant. The prevalence of brucellosis was $13.33 \%$ in pregnant cattle and $10 \%$ in non-pregnant cattle. Among the cattle with the history of reproductive disorder, the animals that experienced abortion showed the highest prevalence of brucellosis $(10 \%)$ followed by those with retained placenta ( $4 \%)$ and repeat breeder $(2.85 \%)$.

Brucella organisms were not isolated from blood samples of the animals as well as from the aborted tissue samples.
Table 1. Prevalence of brucellosis in cattle and buffalo

\begin{tabular}{|l|l|c|c|c|}
\hline $\begin{array}{c}\text { Animal } \\
\text { species }\end{array}$ & \multicolumn{1}{|c|}{ Study areas } & $\begin{array}{c}\text { No. of } \\
\text { sera } \\
\text { tested }\end{array}$ & $\begin{array}{c}\text { No. of } \\
\text { positive } \\
\text { reactors (\%) }\end{array}$ & p value \\
\hline Cattle & $\begin{array}{l}\text { Breeding farm, } \\
\text { Tangail }\end{array}$ & 50 & $11(22)$ & \multirow{2}{*}{0.247} \\
\cline { 2 - 4 } & BAU Dairy Farm & 20 & $1(5)$ & \\
\cline { 2 - 4 } & $\begin{array}{l}\text { Char Nillukia, } \\
\text { Mymensingh }\end{array}$ & 20 & $1(5)$ & \\
\cline { 2 - 4 } & $\begin{array}{l}\text { Char Basur Algi, } \\
\text { Nokla, Sherpur }\end{array}$ & 60 & $10(16.66)$ & \multirow{2}{*}{0.612} \\
\hline \multirow{2}{*}{ Buffalo } & $\begin{array}{l}\text { Bredding Farm, } \\
\text { Tangail }\end{array}$ & 60 & $8(13.33)$ & \\
\hline
\end{tabular}

BAU $=$ Bangladesh Agricultural University

Table 2. Prevalence of brucellosis in cattle and buffalo of different age groups

\begin{tabular}{|l|l|c|c|}
\hline $\begin{array}{c}\text { Animal } \\
\text { species }\end{array}$ & \multicolumn{1}{|c|}{ Age of animals } & $\begin{array}{c}\text { No. of } \\
\text { sera } \\
\text { tested }\end{array}$ & $\begin{array}{c}\text { No. of } \\
\text { positive } \\
\text { reactors } \\
\mathbf{( \% )}\end{array}$ \\
\hline \multirow{4}{*}{ Cattle } & 3 month- 1 year & 35 & $4(11.42)$ \\
\cline { 2 - 4 } & $1-2$ years & 24 & $2(14.28)$ \\
\cline { 2 - 4 } & 2 -4 years & 41 & $7(17.07)$ \\
\cline { 2 - 4 } & Above 4 year & 50 & $9(18)$ \\
\hline \multirow{3}{*}{ Buffalo } & 6 month - 2 years & 4 & $0(0)$ \\
\cline { 2 - 4 } & $2-4$ years & 5 & $0(0)$ \\
\cline { 2 - 4 } & Above 4 years & 51 & $8(15.68)$ \\
\hline
\end{tabular}

\section{Discussion}

This study recorded $15.33 \%$ prevalence of brucellosis in cattle. Prevalence of brucellosis recorded in this study disagreed with the findings of Amin et al. (2004), Rahman et al. (2006) and Rahman et al. (2012) who reported 2\%, 3.8\% and $2.66 \%$ prevalence of brucellosis in cattle in Mymensingh and Sherpur districts of Bangladesh. This variation of prevalence might be due to the difference of animal's age, sex, breed, pregnancy status and the study area, animal management practice, herd size, reproductive diseases and serological tests applied (Gul and Khan, 2007; Kebede et al., 2008). The present study recorded $22 \%$ prevalence of brucellosis in cattle at the breeding farm, Tangail. Rahman et al. (1978) have reported $11.44 \%$ prevalence of brucellosis in Savar dairy farm, $16.16 \%$ in Tangail, and $30.7 \%$ in Pabna milk shed areas of Bangladesh.

In the current study, prevalence of brucellosis in cattle was $17.07 \%$ in 2 to 4 years age group and $18 \%$ over 4 years age group. The difference of prevalence of brucellosis between these groups was statistically significant $(\mathrm{p}<0.05)$. In contrast to the findings of the present study Rahman et al. (2011) reported $1.45 \%$ prevalence of brucellosis in cows aged 2.5 to 4 years and $3.54 \%$ in cows over 4 years of age. Amin et al. (2005) reported $2.3 \%$ and $4 \%$ prevalence in the $<4$ and $>4$ years age group, respectively. Although susceptibility to brucellosis increases with age, it seems to be more commonly associated with sexual maturity (Radostits et al., 2007).

Brucellosis is known to cause abortion, retention of placenta, repeat breeding, infertility and prolonged inter-calving period in animals (Radostits et al., 2007). This study recorded $10 \%$ prevalence of brucellosis in cattle with history of abortion, $4 \%$ prevalence in retained placenta and $2.85 \%$ in repeat breeder cattle. Bachh et al. (1988) reported 89\% prevalence of brucellosis in cattle with a history of abortion. Rahman et al. (2006) recorded $15 \%$ prevalence of brucellosis in aborted cows and $1.45 \%$ in repeat breeder cows and $13.04 \%$ in cows with the history of retained placenta. Ibrahim and Habiballa (1975) reported $14.2 \%$ prevalence of brucellosis in cows with history of abortion. 
Rahman et al. (2006) reported $13 \cdot 04 \%$ prevalence of brucellosis in cows with a history of retained placenta.

In this study, Brucella spp. was not isolated from any of the aborted fetal tissues. Sera obtained from three aborted cattle did not react in RBPT indicating that abortion might not have been caused by Brucella spp. The present study did not isolate Brucella spp. from any of the Brucella seropositive blood samples. Ganado and Bannister (1960) noticed suboptimal recovery rate of Brucella from blood samples. Seropositive animals sometimes yield negative culture results (Alton et al. 1988).

This study recorded $13.33 \%$ seroprevalence of brucellosis in buffalo. Rahman et al. (2012) reported $8.33 \%$ prevalence of brucellosis in buffalo in Mymensingh district. In the present study, buffalo over 4 years of age had higher prevalence $(15.68 \%)$ than other age groups. Similar observations were also recorded by Vikrant et al. (2006) and Puspha and Kumari (2005). Control of brucellosis in animal help reduce the prevalence of brucellosis in humans (WHO, 1981). Therefore, regular surveillance of brucellosis in domesticated livestock is essentia in order to undertake prevention and control measures. RBPT is easy toperform and very helpful in screening and monitoring brucellosis in cattle (OIE, 2008).

\section{Conclusions}

The findings of this study, suggested that brucellosis is endemic in cattle and buffalo in the study areas. However, more surveys are required across the country in order to formulate a policy for prevention and control of brucellosis in livestock and human population.

\section{Acknowledgements}

This study was supported by a financial grant from the Bangladesh Agricultural University Research System (BAURES)

\section{References}

Alton GG, LM Jones, RD Angus and JM Verger, 1988. Techniques for the brucellosis laboratory, Institut National de la Recherche Agronomique, Paris, France.

Alton GG, LM Jones and DE Pietz, 1975. Laboratory technique in brucellosis. $2^{\text {nd }}$ ed. World Health Organization, Geneva, Switzerland.

Amin KMR, MB Rahman, MS Rahman, JC Han, JH Park and JS Chae, 2005. Prevalence of Brucella antibodies in sera of cows in Bangladesh. J Vet Sci, 6: 223-226.

Amin KMR, MB Rahman, SK Sarkar, SML Kabir and MSI Akand, 2004. Serological epidemiology of brucellosis in cattle of the Mymensingh district of Bangladesh. J Anim Sci Vet Adv, 3: 898-900.

Bachh AS, MA Nowsheri, A Rashid AK Raina and S Wani, 1988. Seroprevalence of brucellosis in exotic cattle in Kashmir. Indian J Comp Microbiol Immunol Infect Dis, 9: 23-27.

Behzadi MA and A Mogheiseh, 2011. Outbreak investigation of brucellosis at a kennel in Iran. Pak Vet J, 31: 379-380.

Boschiroli ML, V Foulonge and D O'Callaghan, 2001. Brucellosis: a worldwide Zoonosis: epidemiology simulation model. J Am Vet Med Assoc, 190: 977 -982.

Brahmabhatt MN, RN Varasada, CD Bhong and JB Nayak, 2009. Seroprevalence of Brucella spp. in buffaloes in the central Gujarat. Buffalo Bull, 28: 2.

Collier L, SA Balow and M Sussman, 1998. Microbiology and Microbial Infections. $9^{\text {th }}$ ed. Oxford University Press inc. New York, pp. 819-840.

Corbel MJ, 1997. Brucellosis: An overview. Emer Infect Dis, 3:213-221

Das TM, M Ershaduzzaman, KK Islam, MM Rahman and KBMS Islam, 2008. Surveillance of Brucella melitensis and Brucella abortus from aborted bengal goats in Bangladesh. Res $\mathrm{J}$ Vet Sci, 1: 28-36.
England T, L Kelly, R Jones, A MacMillan and M Wooldridge, 2004. A simulation model of brucellosis spread in British cattle under several testing regimes. Prev Vet Med, 63: 63-73.

Ganado W and W Bannister, 1960. Bacteremia in human brucellosis. Br Med J, 1: 602-603.

Gul ST and A Khan, 2007. Epidemiology and epizootology of brucellosis: A review. Pak Vet J, 27: 145-151.

Gwida M, S Al-Dahouk, F Melzer, U Rosler, H Neubauer and H Tomaso, 2010. Brucellosis - regionally emerging zoonotic disease? Croat Med J, 51: 289-95

Ibrahim AE and N Habiballa, 1975. A survey of brucellosis in Messeriya cows of Sudan. Trop Anim Health Prod, 7: 245-246. Islam MA, MM Khatun, SR Werre, N Sriranganathan and SM Boyle, 2013. A review of Brucella seroprevalence among humans and animals in Bangladesh with special emphasis on epidemiology, risk factors and control opportunities. Vet Microbiol, 166: 317-326.

Kebede T, G Ejeta and G Ameni, 2008. Seroprevalence of bovine brucellosis in smallholder farms in central Ethiopia (WuchaleJida district). Revue Med Vet, 159: 3-9.

Kolman S, MC Maayan, G Gotesman, LA Rozenszajn, B Wolach and R Lang, 1991. Comparison of the BACTEC and lysis concentration methods for recovery of Brucella species from clinical specimens. Eur J Clin Microbiol Infect Dis, 10:647648.

Maadi H, M Moharamnejad and M Haghi, 2011. Prevalence of brucellosis in cattle in Urmia, Iran. Pak Vet J, 31: 81-82.

Montanaro C, R Pavone and M Zaccareli, 1992. An epidemiological survey on an outbreak of brucelliosis in the town of Termoli. Igiene Moderna, 97: 612-623.

Nicoletti P, 1980. The epidemiology of bovine brucellosis. Adv Vet Sci Comp Med, 24: 69-98.

OIE, 2008. Bovine Brucellosis. Manual of Diagnostic Tests and Vaccines for Terrestrial Animals. Office international des Epizootics, 12 rue de prony, 75017 Paris, France.

Pushpa RNR and BP Kumari, 2005. Serosurveillance of brucellosis in bovine and ovine. Indian Vet J, 82: 672-673.

Quinn PJ, ME Carter, B Markey and GR Carter, 1994. Clinical Veterinary Microbiology, Wolfe Publishing, London, UK, pp. 261-267.

Radostits OM, CC Gay, KW Hinchcliff, PD Constable, 2007. Veterinary Medicine: A Textbook of the Diseases of Cattle, Horses, Sheep, Pigs and Goats. Saunders Elsevier, Edinburgh, pp. 963-984.

Rahman MM, TIMF Chowdhury and MUA Chowdhury. 1978. Investigation of brucellosis among cattle. Bangl Vet J, 12: 12-15.

Rahman MS, JC Han, J Park, JH Lee, SK Eo and JS Chae, 2006. Prevalence of brucellosis and its association with reproductive problems in cows in Bangladesh. Vet Rec, 159: 180-182.

Rahman MS, M Her, JY Kim, SI Kang, K Lee, MJ Uddin, A Chakrabartty and SC Jung, 2012. Brucellosis among ruminants in some districts of Bangladesh using four conventional serological assays. African J Microbiol Res 6: 4775-4781.

Rahman MS, MO Faruq, M Her, JY Kim, SI Kang and SC Jung, 2011. Prevalence of brucellosis in ruminants in Bangladesh Vet Med, 56: 379-385.

Shareef JM, 2006. A review of serological investigations of brucellosis among farm animals and humans in northern provinces of Iraq (1974-2004). J Vet Med, 53: 38-40.

Tabak F, E Hakko, B Mete, R Ozaras A Mert and R Ozturk, 2008. Is family screening necessary in brucellosis? infection. Vet Microbiol, 36: 575-577.

Vikrant J, AK Upadhyay, K Mahesh and GS Parihar, 2006. Epidemiological status of brucellosis in domesticated ruminants of Garhwal region in Uttaranchal state. Indian J Vet Med, 26: $130-132$

WHO, 1981. A guide to the diagnosis, treatment and prevention of human brucellosis. World Heath Organization, Geneva, Switzerland.

Yagupsky P and EJ Baron, 2005. Laboratory exposures to Brucella and implications for bioterrorism. Emerg Infect Dis, 11: 1180-1185. 